\title{
Dynamics of Land use Land Cover Change and Mapping of Tree Outside Forest (TOF) in Terai, Nepal
} \author{
Sitaula ${ }^{4}$ \\ ${ }^{1}$ Institute of Forestry, Tribhuvan University, Nepal \\ ${ }^{2}$ Institute of Forestry (Hetauda Campus), Tribhuvan University, Nepal \\ ${ }^{3}$ Institute of Forestry (Pokhara Campus), Tribhuvan University, Nepal \\ ${ }^{4}$ Norwegian University of Life Sciences, Norway
}

Yogendra Yadav ${ }^{1,2 *}$, Bir Bahadur Khanal Chhetri ${ }^{3}$, Santosh Raymajhi ${ }^{3}$, Krishna RajTiwari ${ }^{3}$ and Bishal Kumar

Submission: March 25, 2019; Published: April 29, 2019

*Corresponding author: Yogendra Yadav, Institute of Forestry, Hetauda Campus Hetauda, Tribhuvan University, Office of the Dean, Pokhara, Nepal

Abstract

Due to natural phenomena and various anthropogenic activities, rapid land-use/land-cover (LULC) is happening in the earth. The aim of this study was to evaluate and understand LULC including mapping of tree outside the forest (TOF) coverage in Terai region of Nepal over the period 1990 - 2016. Supervised classification-maximum likelihood algorithm in Arc map software was used for detecting LULC dynamics by using multispectral satellite data obtained from Landsat 5, Global Land Survey Thematic mapper (TM) and Landsat 8 OLI/TIRS. The study site was classified into four major LULC classes i.e. forest, sand, water bodies and others land. There was both increased and decreased of different LULC classes between1990-2016. Except forest, water, sand and others land cover were increased over twenty-six years (1990-2016) between 1990-2016 in the study site. However, the rate of change in forest cover was lowered in the year 2000-2016. Increasing population and inward migration are the main reason behind the decreasing the forest coverage in the study site. However, the health of vegetation was improved between 2000 and 2016 compared to 1990 and 2000 due to contribution of TOF. Overall, anthropogenic activities play vital role in managing natural resources.

Keywords: Land use Land cover change; Change detection; Supervised classification; Tree outside Forest; Terai

\section{Introduction}

Land use and land cover change (LULC) has two separate terminologies that are often used interchangeably [1]. Land cover refers to the biophysical characteristics of earth's surface, including the distribution of vegetation, water, soil, and other physical features of the land. While land use refers to the way in which land has been used by humans and their habitat, usually with an emphasis on the functional role of land for economic activities [2,3]. The LULC change is a major issue of concern with regards to change in global environment [4]. The rapid growth and expansion of urban centers, rapid population growth, scarcity of land, the need for more production, changing technologies are among the many drivers of LULC in the world today [5]. LULC dynamics are widespread, accelerating, and significant processes majorly encouraged by human actions and at the same time resulting to changes that impact human livelihood [6].

LULC is the conversion of different land use types and is the result of complex interactions between humans and the physical environment [7]. Land and its resources have been used to meet the material, social, cultural and spiritual needs of human beings. In the process, human beings modified land uses for various habits and intensities. Conversion of natural forests and grasslands into farming and crop areas to meet the food demand of the everincreasing world population is among the examples [8].

Various techniques of LULC change detection analysis were discussed [9]. It is possible to establish a model to predict the trends in land uses in a certain period of time through the study of past land use changes, which could provide some basis for scientific and effective land use planning, management and ecological restoration in a study area and guidance for regional socio-economic development. TOFs are an important source of wood, other products and environmental services. Such trees include roadside plantings, woodlots, and scattered trees in the landscape, tree in fields, home gardens and orchards. Furthermore, about $80 \%$ of the requirements of the wood-based industries are 
met from TOFs [10]. Depending on prevalent land-use patterns and ecological and economic landscape attributes, TOFs also play a role in carbon sequestration, biodiversity conservation, pollution control and erosion control. The reliable information on TOF presence, spatial distribution, type, quality, and temporal changes is needed, particularly in the larger areas where forest cover is very less such as provinces, countries or regions [11].

The significance of trees outside the forest (TOF) can be observed in several contexts. In countries with low forest cover, TOF resources constitute the main source of wood and non-wood "forest" products, even though trees may be so scattered that the maps produced by FRA 2000 indicate that no forests exist. Trees are found on agricultural lands, in densely populated areas, in fruittree plantations and in-home gardens, which often cover a large proportion of the land. In urban areas trees provide important aesthetic and environmental services in addition to providing shade and greatly increasing the livability of cities. Communities, farmers and herders who do not have access to forests diversify their production and protect their land by maintaining various tree systems on their farms [12].

While the contribution of tree outside forest (TOF) has been appreciated, little is known about the resources itself [12]. TOFs are an important source of wood, other products and environmental services. Such trees include roadside plantings, woodlots, and scattered trees in the landscape, tree in fields, home gardens and orchards. Furthermore, about $80 \%$ of the requirements of the wood-based industries are met from TOFs [10]. Depending on prevalent land-use patterns and ecological and economic landscape attributes, TOFs also play a role in carbon sequestration, biodiversity conservation, pollution control and erosion control. The reliable information on TOF presence, spatial distribution, type, quality, and temporal changes is needed, particularly in the larger areas where forest cover is very less such as provinces, countries or regions [11]. TRF is a dynamic resource and its assessment over large areas, in a relatively shorter period, necessitates use of remote sensing (RS) and geographic information system [13]. It appears that the total forest area decreased by 38,051 ha in the 15 years from 1995 to 2010 at the annual rate of $0.18 \%$ [14].

Remote sensing (RS) and geographic information system (GIS) are needed tools to obtain more precise and timely spatial data of land use and land cover, as well as analyzing the changes in a study area [15]. Remote sensing images can effectively record

Table 1: Detail description of satellite images.

\begin{tabular}{|c|c|c|c|}
\hline Landsat Images & Landsat Scene Identifier & Data Acquired & Cloud Cover \\
\hline Landsat 5 TM & LT51400411990012BKT00 & 12th January 1990 & - \\
\hline Global Land Survey TM & P140R041_7X20001030 & 30th October 2000 & 4.09 \\
\hline Landsat 8 OLI/TIRS & LC81400412016324LGN01 & 19th November, 2016 & \\
\hline
\end{tabular}

land use situations and provide an excellent source of data, from which updated LULC information and changes can be extracted, analyzed and simulated efficiently through certain means [16]. Therefore, remote sensing is widely used in the detection and monitoring of land use at different scales [17]. GIS provides a flexible environment for collecting, storing, displaying and analyzing digital data necessary for change detection [18]. Land use research programs at a global scale have developed central to international climate and environmental change research since the launch of land use and land cover (LULC) change project [19]. LULC has two separate terminologies that are often used interchangeably [1]. Land cover refers to the biophysical characteristics of earth's surface, including the distribution of vegetation, water, soil, and other physical features of the land. While land use refers to the way in which land has been used by humans and their habitat, usually with an emphasis on the functional role of land for economic activities [2].

Rapid urbanization efforts in change in TOF in an urban area. The temporal and spatial change pattern of TOF is essential form well environmental base planning. The study of TOF change pattern of Dhangadhi and Fulkathi will support in quantifying of Carbon storage in urban region of Nepal. An assessment of group and scatter TOFs is also done in this paper which will give the exact quantity of TOFs at this study area by using Orbview-2 high resolution image.

\section{Methodology}

\section{Study area}

The study area covers an area of $8,034.7 \mathrm{Km} 2$ of two VDC named as Dhangadhi and Fulkathi. These VDCs lie between Latitude 26.720 and $26.80^{\circ}$ South and Longitude $86.34^{\circ}$ and $86.43^{\circ}$ East The study area is in southern part of Terai region of eastern Nepal.

\section{Data collection}

\section{Satellite data}

Satellite data that comprised of three years (1990, 2000 and 2016) multi-temporal satellite imageries i.e. LANDSAT 5, Global Land Survey Thematic mapper (TM), and Landsat 8 OLI/ TIRS imageries acquired from the USGS GLOVIS website. Other additional data i.e. ancillary data included shape file of the study site from Department of survey, Nepal. Worldview-2 image acquired and used to delineate the group and scatter trees in the study site (Table 1). 


\section{Image processing and classification}

Pre-processing of satellite images before detection of changes is a very vital process with exclusive aim of building a more direct association between the biophysical phenomena on the ground and the acquired data [20]. The main objective of image classification is to change the pixel value in the form of thematic information. Satellite data were pre-processed for composite and sub-setting of the image on the basis of Area of Interest (AOI) by using Arc map. Image classification prepared in order to allocate different spectral signatures from the LANDSAT datasets to different Land use land cover class (LULC). Different color composites used to improve visualization of different objects of the images. Images were classified based on reflectance

Table 2: Description of land use land cover in the study site. characteristics of the different LULC types. Near infrared (NIR), short wave infrared (WIR), and Red bands were combined for the identifying varied levels of vegetation and separating different of vegetation. Besides, this image classification was supplemented through field visit. Furthermore, training samples for predetermined LULC type were selected by delineating polygons around representative sites. Pixels of predetermined LULC were enclosed for developing spectral signatures file [21]. The Maximum Likelihood Classification is the most extensively used per-pixel method by considering spectral information of land cover classes [4]. Maximum Likelihood classifier (MAXLIKE) of supervised classification were used classified the images into four major LULC classes i.e. forest, sand, water, and others (Table 2).

\begin{tabular}{|c|c|}
\hline Land Cover & Descriptions \\
\hline Forest & The area with evergreen trees mainly growing naturally in the reserved land, along the rivers, roadsides, farmland, \\
orchards, and plantation patch.
\end{tabular}

\section{Post classification}

Post-classification modification is done to mend classification accuracy and reduction of mis-classifications [22]. After image classification, ground verification was done in order to check the accuracy of the classified LULC map. Based on the ground verification, necessary correction and adjustments were made for eliminating errors pixels. The map from classification of timer period 1, 2 and 3 i.e. 1990, 2000, and 2016, respectively. The transaction matrix between 1990 and 2000, 2000 and 2016, and overall 1990-2016 were prepared.

\section{Delineation of scatter and group tree in study site}

Very high-resolution image of Wordview-2 with pixel size $2 \mathrm{~m}$ used for delineation of scatter and group tree in the study site.

\section{Normalized Difference Vegetation Index (NDVI)}

NDVI was calculated for study area to know the vegetation health condition for three different years by using the red band and infrared band with help of following formula [23].

\section{Accuracy assessment}

If the classification data are to be beneficial in finding of change analysis, it is vital to accomplish accuracy assessment for individual classification [24]. It exposes the extent of correspondence between what is on the ground and the classification results. It is important to be able to derive accuracy for individual classification if the resulting data are to be useful in change detection analysis. In this study, accuracy assessment was done for the Landsat 8 OLI/TIRS 2016 satellite image, for which the ground truth data likely equates. An overall accuracy was calculated by dividing the sum of the correctly classified sample units by the total number of sample units.

\section{Results and Discussion}

\section{Classification of images}

The overall classification accuracy for three years was ranged between $91-96 \%$. The study area was defined to have four major land use and land cover categories i.e. Forest, Sand, Water Bodies and others. The land use land cover classification over twenty-six years (1990-2016) was shown in Figure 1.

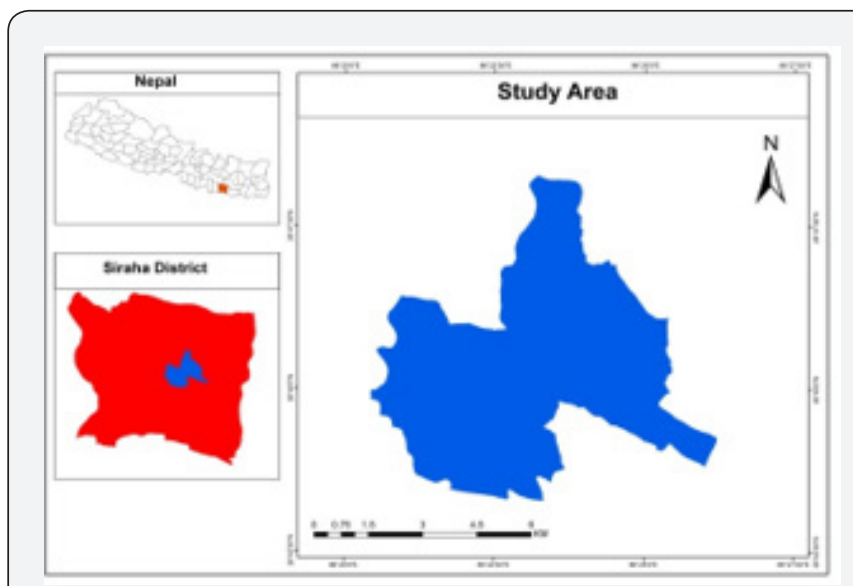

Figure 1: Map of study area. 


\section{Gross percentage change in LULC classes between 1990-2016}

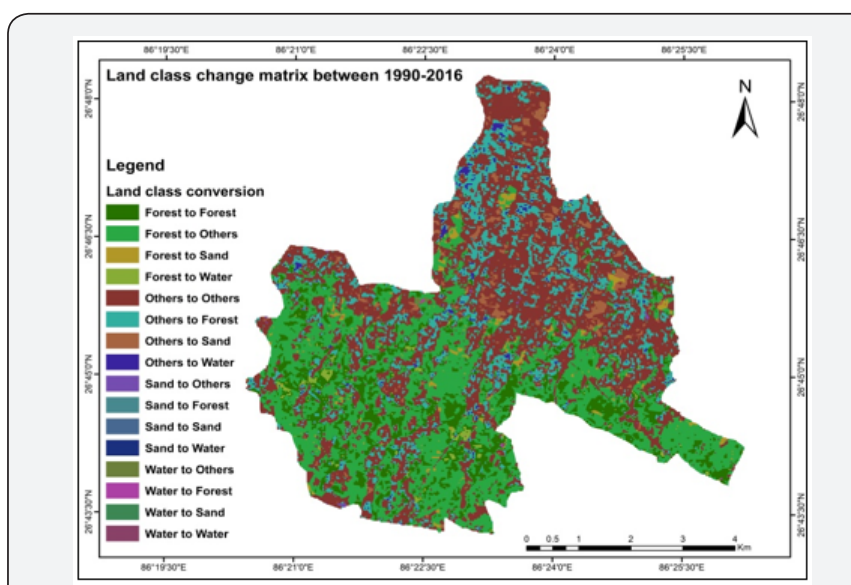

Figure 2: Land cover change dynamics between 1990 to 2000

Overall, water, sand and others land cover were increased by $11 \%, 15 \%$, and $0.7 \%$, respectively over twenty-six years $(1990$ 2016) (Figure 2 \& 3). However, forest cover was decreased by $1.9 \%$ between $1990-2016$ in the study site.

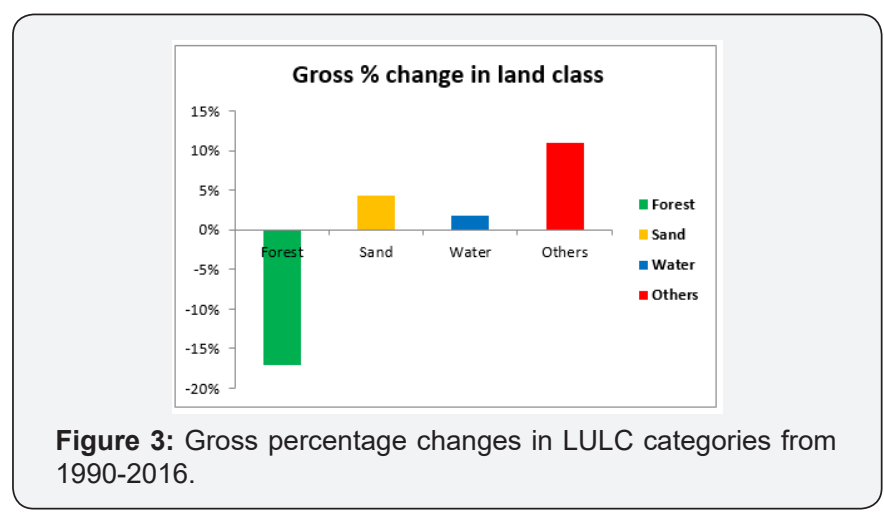

Change in LULC for the years of 1990, 2000, and 2016

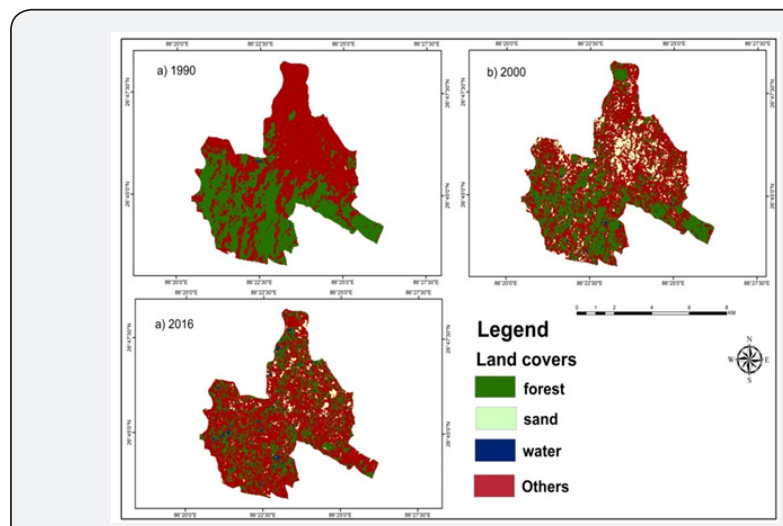

Figure 4: Land classification map in three different year.

The study shows that the forest cover is the most dominant land cover in Nepal that comprises about 6,200,000 ha forest cover [25]. Over twenty six year period, forest cover was significantly decreased in the study site (Figure 4-6). Forest cover was significantly decreased by $2.69 \%$ between 1990-2000 (Figure
5). Similar trend was observed between 2000-2016 (Figure 6). However, the rate of change in forest cover was lowered in the later period. This could be due to increment of migration from mid hills to study site (Dhangadhi and Fulkathi). Consequently, forest was converted in to other land i.e. settlements, agriculture land etc. for supporting livelihood of growing population. Between1990-2000, water body content was dramatically increased by $26.67 \%$ (Figure 5) since the Government gave subsidy for the promotion of fish industries for improving livelihood of local people during this period. Furthermore, water logging due to over flooding leads to higher water body content in the study site. Like water body, sand area was enormously increased by $58.26 \%$ between 1990 and 2000 (Figure 5). As study site is in the lower range of Siwalik, sand might be deposited due to soil erosion especially during the monsoon season resulting higher water body cover in the study site. However, sand area was decreased by $5.12 \%$ between 2000 and 2016 (Figure 6). This could be due to conversion of sand area in to other usable land including increment of plantation during this period. In contrast to water body and sand area, other land covers i.e. agriculture and urban area was slightly decreased by 2\% between 1990 and 2000 (Figure 5). However, the other land class increased between 2000 and 2016 due to urbanization and urban migration in the study site.

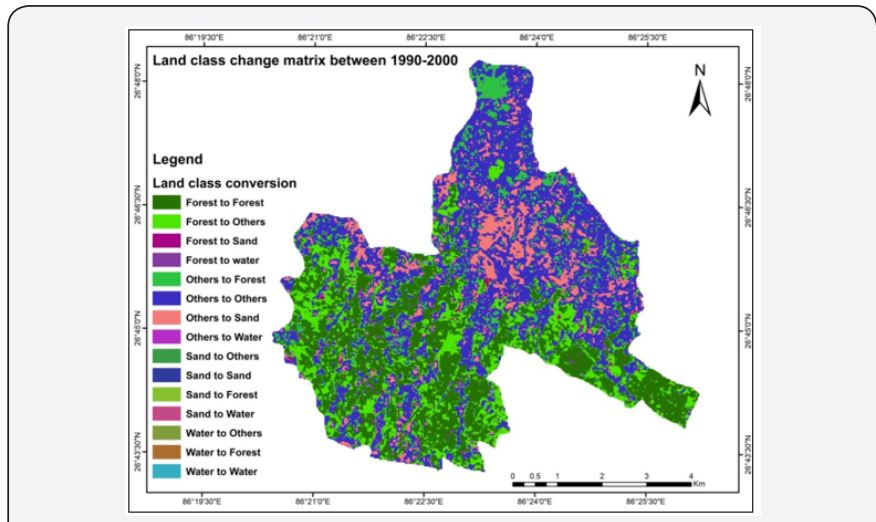

Figure 5: Land cover change dynamics between 1990 to 2000.

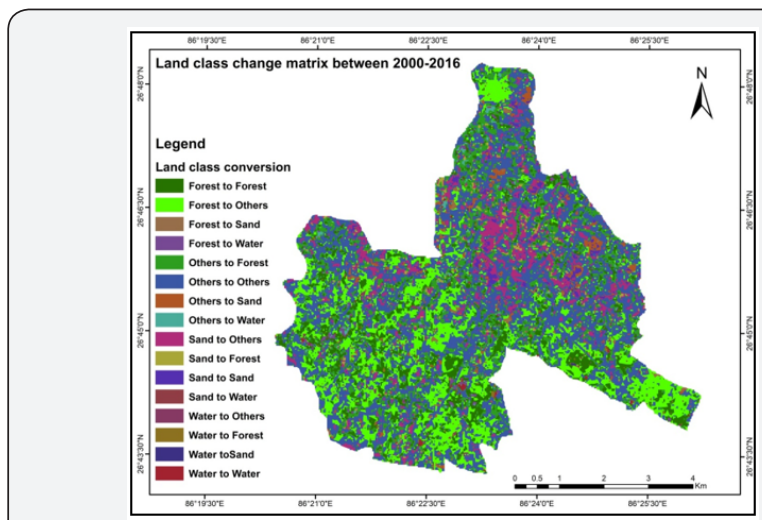

Figure 6: Land cover change dynamics between 2000 to 2016.

Land cover change matrix showed that 744.1 ha of forest area converted in to 26.7 ha of sand, 41.2 ha water, and 6676.2 ha of 
others between 1990-2000 (Appendix 1). Similarly, 913.3ha of forest area converted into 28.8ha of sand, 35.1ha water, and 849.4 ha of others between 2000 and 2016 (Appendix 2). Interestingly, around 313.3ha of others land converted into forest between 1990 and 2000 (Appendix 1). Similar trend was observed between 2000 and 2016 (Appendix 2). This could be due to lack of irrigation facilities in the study site which promotes plantation of tress species i.e. mangoes, eucalyptus for supporting their livelihood instead of cultivating crops. This can be display in the Figure $7 \& 8$ where about total area of forest, scatter TOF covers 453.70ha while group TOF covers 592.29 ha in study site in the year 2016 (Figure 7 \& 8).

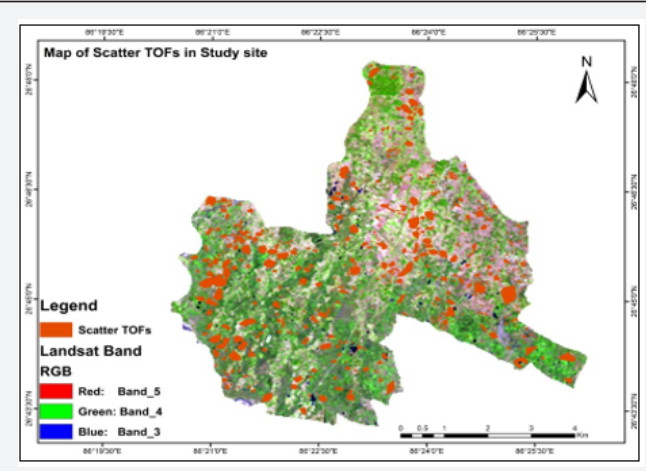

Figure 7: Scatter TOFs in study area.

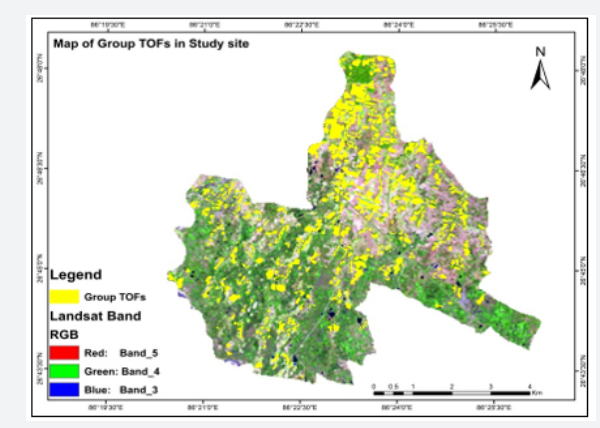

Figure 8: Group TOFs in study area.

\section{Normalized Difference Vegetation Index (NDVI)}

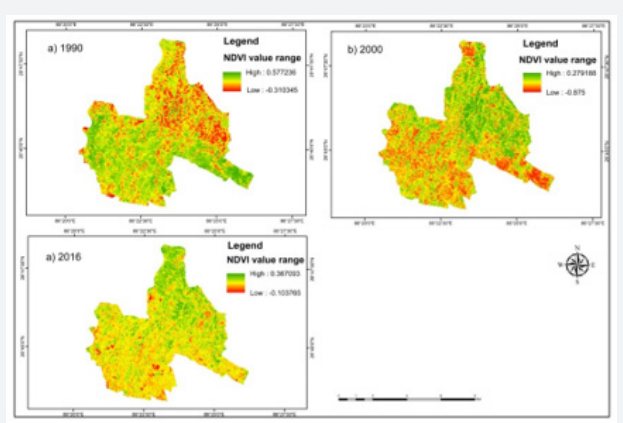

Figure 9: NDVI value range in different year in the study site.

The NDVI value indicates health of vegetation. Thus, the higher NDVI value, the better will be the vegetation health [26]. The NDVI ranges were -0.31 to $0.577,-0.875$ to 0.27 and -0.10 to
0.36 in 1990, 2000 and 2016, respectively (Figure 9). Decreasing positive value of NDVI between 1990 and 2000 showed that health of vegetation was degraded. In contrast, increment of NDVI value showed that the health of vegetation improved between 2000 and 2016 due to promotion of TOF in the study site (Figure 9).

\section{Conclusion}

Except forest, water, sand and others land cover was increased over twenty-six years (1990 and 2016) in the study site. Forest cover was decreased by $1.9 \%$ between 1990 and 2016 in the study site. This could be due to growing population in the study site. Consequently, forest area was converted into settlements, agriculture land etc. for supporting livelihood of growing population. Between 1990 and 2000, around 313.3 ha of others land converted into forest. Similar trend observed between 2000 and 2016 in the study site. The health of vegetation in the study site was improved between 2000 and 2016 compared to 1990 and 2000 due to contribution of TOF. Overall, this study shows that anthropogenic activities play significant role on LULC. This study can be reference for decision-makers and planners to take relevant action towards promotion of TOF which can address land degradation issues especially in the Terai region of Nepal.

\section{Acknowledgement}

The authors gratefully acknowledge to the editors and anonymous reviewers for their critical comments and suggestions. We would like to acknowledge the financial support provided by the NORHED project IOF Dean Office Pokhara.

\section{References}

1. Rawat JS, Kumar M (2015) Monitoring land use/cover change using remote sensing and GIS techniques: A case study of Hawalbagh block, district Almora, Uttarakhand, India. The Egyptian Journal of Remote Sensing and Space Science 18(1): 77-84.

2. McConnell WJ (2015) Land Change: The Merger of Land Cover and Land use Dynamics. International Encyclopedia of the Social \& Behavioral Sciences (Second Edition), pp. 220-223.

3. Lambin E (2006) Land cover assessment and monitoring. Encyclopedia of Analytical Chemistry: Applications, Theory and Instrumentation. Encyclopedia of Analytical Chemistry: Applications, Theory and Instrumentation.

4. Qian J, Zhou Q Hou Q (2007) Comparison of pixel-based and objectoriented classification methods for extracting built-up areas in arid zone. In ISPRS workshop on updating Geo-spatial databases with imagery \& the 5th ISPRS workshop on DMGISs. National Geomatics Center of China sponsored, pp. 163-171.

5. Barros JX (2004) Urban growth in Latin American cities-Exploring urban dynamics through agent-based simulation (Doctoral dissertation, University of London).

6. Agarwal C, Green GM, Grove JM, Evans TP, Schweik CM (2002) A review and assessment of land-use change models: dynamics of space, time, and human choice (Vol. 297). Newton Square, PA: US Department of Agriculture, Forest Service, Northeastern Research Station.

7. Pielke RA, Pitman A, Niyogi D, Mahmood R, McAlpine C, et al. (2011) Land use/land cover changes and climate: modeling analysis and observational evidence. Wiley Interdisciplinary Reviews: Climate Change 2(6): 828-850. 
8. Solh M (2011) Ensuring food security in a changing climate: How can science and technology help. Food security and climate change in dry areas, pp. 5-12.

9. Lu D, Mausel P, Brondizio E, Moran E (2004) Change detection techniques. International journal of remote sensing 25(12): 23652401.

10. Chave J, Condit R, Aguilar S, Hernandez A, Lao S, et al. (2004) Error propagation and scaling for tropical forest biomass estimates. Philos Trans R Soc Lond B Biol Sci 359(1443): 409-420.

11. FAO (2005) Tree outside forest; Food and Agricultural Organization of the United Nations, Rome.

12. FAO (2006) Global Forest Resources Assessment 2005: Progress towards Sustainable Forest Management. FAO Forestry Paper 147 Food and Agriculture Organization of the United Nations, Rome, Italy.

13. Dadhwal VK, Singh S, Patil P (2009) Assessment of Phytomass Carbon Pools in Forest Ecosystems in India. NNRMS Bulletin no. 41, p. 57.

14. DFRS (2015) State of Nepal's Forests. Forest Resource Assessment (FRA) Nepal, Department of Forest Research and Survey (DFRS). Kathmandu, Nepal.

15. Reis S (2008) Analyzing land use/land cover changes using remote sensing and GIS in Rize, North-East Turkey. Sensors 8(10): 6188-6202.

16. Pradhan B, Lee S, Mansor S, Buchroithner M, Jamaluddin N, et al. (2008) Utilization of optical remote sensing data and geographic information system tools for regional landslide hazard analysis by using binomial logistic regression model. Journal of Applied Remote Sensing 2(1): 023542 .

17. Mishra VN, Rai PK, Kumar P, Prasad R (2016) Evaluation of land use/land cover classification accuracy using multi-resolution remote sensing images. In Forum geographic, University of Craiova Department of Geography, 15(1): 45.
18. Zeleke G, Hurni H (2001) Implications of land use and land cover dynamics for mountain resource degradation in the Northwestern Ethiopian highlands. Mountain research and development 21(2): 184192.

19. Chen J, Chen J, Liao A, Cao X, Chen L, et al. (2015) Global land cover mapping at $30 \mathrm{~m}$ resolution: A POK-based operational approach. ISPRS Journal of Photogrammetry and Remote Sensing 103: 7-27.

20. Coppin P, Jonckheere I, Nackaerts K, Muys B, Lambin E (2004) Review Article Digital change detection methods in ecosystem monitoring: a review. International journal of remote sensing 25(9): 1565-1596.

21. Cheruto MC, Kauti MK, Kisangau PD, Kariuki PC (2016) Assessment of land use and land cover change using GIS and remote sensing techniques: a case study of Makueni County, Kenya. Journal of Remote Sensing \& GIS 5: 175.

22. Harris PM, Ventura SJ (1995) The integration of geographic data with remotely sensed imagery to improve classification in an urban area. Photogrammetric engineering and remote sensing 61: 993-998.

23. Rouse J, Haas RH, Schell JA, Deering DW (1974) Monitoring vegetation systems in the Great Plains with ERTS. NASA special publication 351: 309.

24. Owojori A, Xie H (2005) Landsat Image-Based LULC Changes of San Antonio, Texas Using Advanced Atmospheric Correction and ObjectOriented Image Analysis Approaches. 5th International Symposium on Remote Sensing of Urban Areas, Tempe, USA.

25. Uddin K, Abdul Matin M, Maharjan S (2018) Assessment of Land Cover Change and Its Impact on Changes in Soil Erosion Risk in Nepal. Sustainability 10(12): 4715.

26. West H, Quinn N, Horswell M, Paul W (2018) Performance of Sentinel-2 NDVI for assessing the relationship between vegetation and soil moisture under extreme drought conditions. In: European Geosciences Union General Assembly, Vienna, Austria.

Your next submission with Juniper Publishers will reach you the below assets

- Quality Editorial service

- Swift Peer Review

- Reprints availability

- E-prints Service

- Manuscript Podcast for convenient understanding

- Global attainment for your research

- Manuscript accessibility in different formats

( Pdf, E-pub, Full Text, Audio)

- Unceasing customer service

Track the below URL for one-step submission https://juniperpublishers.com/online-submission.php 